\title{
Asymptomatic hyperuricemia and coronary flow reserve in patients with metabolic syndrome
}

\author{
Seoyoung C. Kim ${ }^{1,2^{*}}$ (D, Marcelo F. Di Carli ${ }^{3,4}$, Rajesh K. Garg ${ }^{5}$, Kathleen Vanni ${ }^{2}$, Penny Wang ${ }^{2}$, Alyssa Wohlfahrt ${ }^{2}$, \\ Zhi Yu², Fengxin Lu' ${ }^{2}$ Anarosa Campos ${ }^{2}$, Courtney F. Bibbo ${ }^{3}$, Stacy Smith ${ }^{6}$ and Daniel H. Solomon ${ }^{1,2}$
}

\begin{abstract}
Background: Patients with metabolic syndrome (MetS) are at increased risk of asymptomatic hyperuricemia (i.e., elevated serum uric acid (SUA) level without gout) and cardiovascular disease. We conducted a cross-sectional study to examine associations between SUA levels and coronary flow reserve and urate deposits in carotid arteries in patients with asymptomatic hyperuricemia and MetS.

Methods: Adults aged $\geq 40$ years with MetS and SUA levels $\geq 6.5 \mathrm{mg} / \mathrm{dl}$, but no gout, were eligible. Using a stress myocardial perfusion positron emission tomography (PET), we assessed myocardial blood flow (MBF) at rest and stress and calculated coronary flow reserve (CFR). CFR $<2.0$ is considered abnormal and associated with increased cardiovascular risk. We also measured insulin resistance by homeostatic model assessment (HOMA-IR) method and urate deposits using dual-energy CT (DECT) of the neck for the carotid arteries.

Results: Forty-four patients with the median age of 63.5 years underwent a blood test, cardiac PET and neck DECT scans. Median (IQR) SUA was $7.8(7.1-8.4) \mathrm{mg} / \mathrm{dL}$. The median (IQR) CFR was abnormally low at 1.9 (1.7-2.4) and the median (IQR) stress MBF was $1.7(1.3-2.2) \mathrm{ml} / \mathrm{min} / \mathrm{g}$. None had urate deposits in the carotid arteries detected by DECT. In multivariable linear regression analyses, SUA had no association with CFR ( $\beta=-0.12, p=0.78)$ or stress MBF ( $\beta=-0.52$, $p=0.28)$. Among non-diabetic patients $(n=25)$, SUA was not associated with HOMA-IR $(\beta=2.08, p=0.10)$.

Conclusions: Among MetS patients with asymptomatic hyperuricemia, we found no relationship between SUA and CFR, stress MBF, and insulin resistance. No patients had any DECT detectable subclinical urate deposition in the carotid arteries.
\end{abstract}

Keywords: Uric acid, Metabolic syndrome, PET/CT, DECT, Coronary blood flow

\section{Background}

The association between hyperuricemia, with and without gout, and risk of coronary artery disease (CAD), metabolic syndrome and kidney disease has been well-reported [1-9]. However, debate persists as to whether serum uric acid (SUA) has a causal role in the development of

\footnotetext{
* Correspondence: sykim@bwh.harvard.edu

The interim analysis of this study was presented at the 2016 American College of Rheumatology Meeting in Washington DC, USA.

'Division of Pharmacoepidemiology and Pharmacoeconomics, Department of Medicine, Brigham and Women's Hospital, Harvard Medical School, 1620 Tremont St, Suite 3030, Boston, MA 02120, USA

${ }^{2}$ Division of Rheumatology, Immunology, and Allergy, Department of Medicine, Brigham and Women's Hospital, Harvard Medical School, Boston, MA, USA Full list of author information is available at the end of the article
}

these conditions. Metabolic syndrome or diabetes is a known risk factor for CAD as results of macro- and micro-angiopathy related to diabetes $[10,11]$. Patients with both metabolic syndrome and hyperuricemia may be at increased cardiovascular risk.

Positron emission tomography (PET)-measured coronary flow reserve (CFR) - the ratio of peak hyperemic myocardial blood flow (MBF) over that at rest as- is shown to be a reliable imaging marker of clinical cardiovascular risk [12, 13]. A reduced CFR can be a sign of flowlimiting CAD [14] and presence of coronary vascular dysfunction involving smaller vessels, which increases the severity of inducible myocardial ischemia and sub-clinical myocardial injury beyond the effects of

(c) The Author(s). 2018 Open Access This article is distributed under the terms of the Creative Commons Attribution 4.0 International License (http://creativecommons.org/licenses/by/4.0/), which permits unrestricted use, distribution, and reproduction in any medium, provided you give appropriate credit to the original author(s) and the source, provide a link to the Creative Commons license, and indicate if changes were made. The Creative Commons Public Domain Dedication waiver (http://creativecommons.org/publicdomain/zero/1.0/) applies to the data made available in this article, unless otherwise stated. 
upstream coronary obstruction [15]. CFR less than 2.0 has been shown to be independently associated with risk for CAD, heart failure as well as cardiovascular death $[12,13$, $16,17]$. While the association between gout, hyperuricemia and cardiovascular disease has been extensively studied, it has not been studied whether asymptomatic hyperuricemia (i.e., hyperuricemia without known diagnosis of gout) is associated with coronary vascular function measured with PET-CFR.

Dual-energy computed tomography (DECT) is a highly specific imaging modality that allows specific detection and volume measurement of urate crystals in the joints or tendons among patients with tophaceous gout $[18,19]$. In a recent meta-analysis of 8 studies on DECT diagnostic performance, the pooled sensitivity was $84.7 \%$ and the pooled specificity $93.7 \%$ for gout [20]. DECT also had the positive predictive value of $87 \%$ for diagnosing gout in patients with a history of gout during their intercritical period [21]. While in some studies up to $24 \%$ had DECT-positive urate deposits in the joints of asymptomatic hyperuricemic patients [22, 23], no data is available whether urate crystals exist and/or can be detected in the vasculature using DECT scans.

We, therefore, conducted a cross-sectional study to determine the association between SUA levels and CFR, insulin resistance, renal function, and systemic inflammation. In addition, we used DECT scans to examine whether we could find/visualize subclinical urate deposits in carotid arteries among patients with asymptomatic hyperuricemia and metabolic syndrome.

\section{Methods}

\section{Study population}

For this cross-sectional study, eligible patients were men and women aged 40 years or older who had asymptomatic hyperuricemia defined as SUA $\geq 6.5 \mathrm{mg} / \mathrm{dL}$ and metabolic syndrome defined by the presence of at least 3 out of 5 traits in the National Cholesterol Education Program Adult Treatment Panel III (NCEP-ATP III) criteria [i.e., obesity with body mass index $(\mathrm{BMI})>29.4 \mathrm{~kg} / \mathrm{m}^{2}$, high triglyceride level, low high-density lipoprotein level, hypertension, or hyperglycemia] [24]. We excluded pregnant or nursing women, patients with diagnosis of gout, symptomatic coronary artery disease or pulmonary disease, moderate-to-severe valvular heart disease requiring surgery, end-stage renal disease, renal replacement therapy, active malignancy requiring treatment, or those who used xanthine oxidase inhibitors, colchicine or probenecid. Details of this study cohort is described elsewhere [25].

The study protocol was approved by the Institutional Review Board of the Brigham and Women's Hospital. Written informed consent was obtained in all included patients before participating the study.

\section{Patient recruitment}

We recruited patients from the Partners Healthcare Biobank (https://biobank.partners.org) or several clinical sites of the Brigham and Women's Hospital (BWH). After we identified potential patients who met the study criteria through medical record review, we contacted those patients via letter. All patients went through a structured pre-screen phone call or a visit. We measured the SUA level by enzymatic colorimetric assay at the screening visit, unless a SUA value $\geq 6.5 \mathrm{mg} / \mathrm{dL}$ from within the last year was available in their medical record.

\section{Positron emission tomographic imaging}

Patients underwent a whole-body PET/computed tomography scanner (Discovery RX or STE LightSpeed 64, GE Healthcare, Milwaukee, WI) after at least $4 \mathrm{~h}$ of fasting. The study protocol for PET is similar to our previous work described elsewhere [26]. Briefly, ${ }^{13} \mathrm{~N}$-ammonia was used as a flow tracer at rest and stress for PET, [27] and an intravenous infusion of regadenoson was given as a stressor. We quantified $\mathrm{MBF}$ in $\mathrm{ml} / \mathrm{min} / \mathrm{g}$ during rest and peak stress using ${ }^{13} \mathrm{~N}$-ammonia and calculated CFR as the ratio of stress MBF over rest MBF [28-31]. Clinically relevant cardiologic variables including heart rate, blood pressure, and 12-lead ECG were assessed at baseline and throughout the test. With commercially available software, we calculated left ventricular ejection fraction (LVEF) at rest and stress from gated myocardial perfusion images. In addition, summed rest, stress, and difference scores were computed. Higher summed stress scores reflect larger areas of myocardial scar and ischemia. In general, normal scans have the summed stress score $\leq 3$ [32-34].

\section{Dual-energy CT (DECT) imaging}

We obtained DECT scans of the neck using a dual-source CT scanner operated at DECT mode (SOMATOM Definition Flash, Siemens Medical Systems, Forchheim, Germany) at the tube potentials of $80 \mathrm{kV}$ and $140 \mathrm{kV}$ with an additional tin filter. We then used a commercial software post-processing program ('Gout', Syngo CT Workplace, Siemens Medical Systems) to produce digital colorcoded images, where MSU deposits were marked as green. As a part of the main study, the study patients also underwent a DECT scan of the foot described elsewhere [25].

\section{Markers of systemic inflammation and metabolic risks}

We measured markers of systemic inflammation including interleukin (IL)-6 and high-sensitivity C-reactive protein (hs-CRP), and markers of metabolic risks including lipid, insulin and glucose levels at fasting. IL-6 level was assessed by enzyme-linked immunosorbent assay (ELISA). Insulin level was measured using a 2-site electrochemiluminescent immunoassay on the Roche automated platform. We then quantified insulin resistance using 
the Homeostatic Model Assessment-Insulin Resistance (HOMA-IR, normal <3) method [35]. We also collected information on a number of predefined variables potentially related to hyperuricemia or cardiometabolic risk, including demographics, body mass index (BMI), smoking status, comorbidities, and medication use. In addition, we measured serum creatinine and urine microalbumin and estimated glomerular filtration rate (eGFR) for the kidney function.

\section{Statistical analysis}

We used descriptive statistics to characterize the study cohort. Because data were not normally distributed, we used natural $\log$ transformation of SUA levels, CFR, $\mathrm{MBF}$, and other laboratory results as dependent variables in regression models. For the primary analysis, we used unadjusted and multivariable linear regression models to examine the association between SUA levels and coronary vascular function (i.e., CFR and stress $\mathrm{MBF}$ ) in the main cohort. Our final models were adjusted for age, sex, BMI, summed stress score (i.e., a strong indicator of myocardial scar and ischemia), serum creatinine, IL-6, hs-CRP, and presence of diabetes. Because prior myocardial scar or ischemia is a major determinant of CFR, we conducted a sensitivity analysis in which we performed multivariable linear regression models only in patients with summed stress scores which measure the extent of myocardial scar and ischemia $\leq 3$ [32-34]. For the association between SUA and HOMA-IR, we ran unadjusted and multivariable linear regression in a subgroup of patients without diabetes.

Because no patients had subclinical urate deposits in the neck DECT scan, no further analysis was done for that variable. We used SAS 9.4 Statistical Software (SAS Institute Inc., Cary, NC) for all analyses.

\section{Results}

A total of 131 patients were consented into the study. Of these, 78 (59.5\%) were excluded because of absence of hyperuricemia. One patient did not complete the screening blood draw. Eight patients who had hyperuricemia did not complete the full study; three declined to participate further, three patients completed only a portion of the study, and two were withdrawn by the study investigator. Forty-four completed the full study (see Fig. 1). Median age (IQR) was 65 (64-67) years, median (IQR) SUA was $5.5(5.0-6.1) \mathrm{mg} / \mathrm{dL}$ and $66.7 \%$ were male in 86 patients who were consented but did not complete the study visit. Among those who completed the study, median [Interquartile range (IQR)] age was 63.5 (58.0-68.5) years, median (IQR) SUA was 7.8 (7.1-8.4) $\mathrm{mg} / \mathrm{dL}$ and $40.9 \%$ were male (Table 1 ). The median (IQR) BMI was $34.7(32.0-41.8) \mathrm{kg} / \mathrm{m}^{2}$ and $43.2 \%$

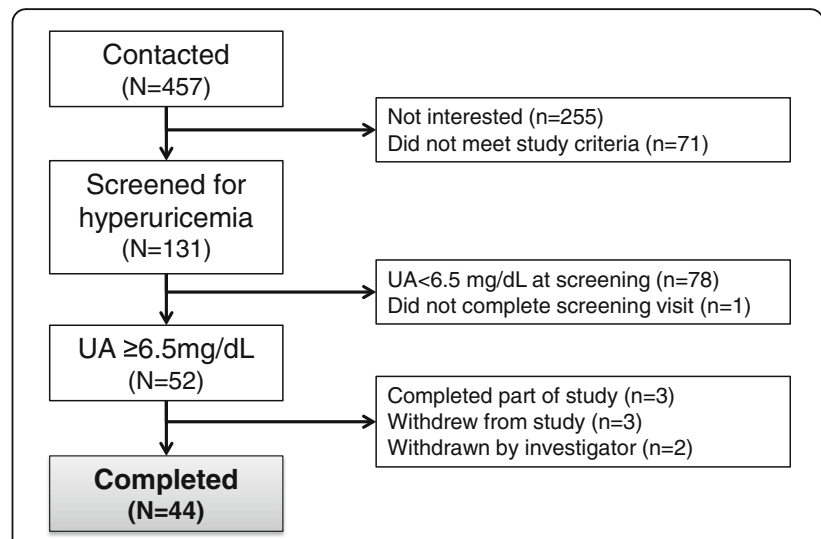

Fig. 1 Patient recruitment flow chart. Among 457 patients we contacted, 52 (11.4\%) patients had hyperuricemia defined as having serum uric acid (UA) $\geq 6.5 \mathrm{mg} / \mathrm{dL}$, and 44 (9.6\%) completed the study

had type 2 diabetes. Half of patients had a family history of MI and $11.4 \%$ had a history of MI.

The median (IQR) CFR was 1.9 (1.7-2.4) and median (IQR) stress MBF was $1.7(1.3-2.2) \mathrm{ml} / \mathrm{min} / \mathrm{g}$. Twenty-six (57.8\%) patients had CFR less than 2.0 known to be associated with worse cardiovascular outcomes in a general referral population [16]. Twenty-eight (62.2\%) had a normal summed stress score $(\leq 3)$ which is a marker of prior myocardial scar or ischemia [32-34]. The median (IQR) HOMA-IR was 4.8 (3.4-6.5). In the unadjusted linear regression analyses (Table 2), SUA was not associated with coronary vascular function (CFR and stress MBF), systemic inflammation (IL-6 and hs-CRP), and insulin resistance (HOMA-IR). However, SUA had a positive association with serum creatinine ( $\beta=0.87, p=0.01)$ and an inverse association with eGFR $(\beta=-1.23, p=0.002)$. In the final multivariable linear regression model adjusting for age, sex, diabetes, BMI, summed stress score, serum creatinine, IL-6 and hs-CRP (Table 3), SUA was not associated with CFR $(\beta=-0.12, p=0.78)$ or stress $\operatorname{MBF}(\beta=-0.52, p=0.28)$.

No association between SUA, CFR and stress MBF was noted in a sensitivity analysis limiting to 28 patients with a normal summed stress score $(\leq 3)$. Among patients with no diabetes $(n=25)$, the median (IQR) HOMA-IR was $4.6(3.8-5.7)$ and there was no significant association between SUA and HOMA-IR ( $\beta=2.08, p=0.1)$. None had DECT-detectable subclinical urate deposits in the neck, while $15 \%$ of these patients had subclinical urate deposits in the foot DECT scan (results published elsewhere) [25].

\section{Discussion}

Over the past few decades, growing evidence from a number of large epidemiologic studies suggests that a higher SUA is independently associated with an increased risk of cardiovascular disease including CAD [2-9, 36, 37]. 
Table 1 Study patient characteristics

\begin{tabular}{|c|c|}
\hline Total number of patients & 44 \\
\hline \multicolumn{2}{|l|}{ Demographic } \\
\hline Age, year, median (IQR) & $63.5(58.0-68.5)$ \\
\hline Male, n (\%) & $18(40.9)$ \\
\hline \multicolumn{2}{|l|}{ Comorbidities } \\
\hline Body mass index, kg/m², median (IQR) & $34.7(32.0-41.8)$ \\
\hline Current smoking, n (\%) & $3(6.8 \%)$ \\
\hline Type 2 diabetes, $\mathrm{n}(\%)$ & $19(43.2 \%)$ \\
\hline Insulin use, n (\%) & $6(13.6 \%)$ \\
\hline $\mathrm{Ml}, \mathrm{n}(\%)$ & $5(11.4 \%)$ \\
\hline Statin use, n (\%) & $33(75.0 \%)$ \\
\hline Family history of Ml, n (\%) & $22(50.0 \%)$ \\
\hline 10-year Reynolds risk score, \%, median (IQR) & $11.2(4.2-19.4)$ \\
\hline \multicolumn{2}{|l|}{ Laboratory data, median (IQR) } \\
\hline Uric acid, mg/dL & $7.8(7.1-8.4)$ \\
\hline Total cholesterol, mg/dL & $167.5(153.0-198.0)$ \\
\hline Triglycerides, mg/dL & $172.5(115.0-201.5)$ \\
\hline $\mathrm{HDL}, \mathrm{mg} / \mathrm{dL}$ & $44.0(38.0-54.0)$ \\
\hline $\mathrm{LDL}, \mathrm{mg} / \mathrm{dL}$ & $87.0(76.5-116.5)$ \\
\hline Fasting blood glucose, mg/dL & $100.5(92.5-135.0)$ \\
\hline Serum creatinine, mg/dL & $0.9(0.8-1.2)$ \\
\hline $\mathrm{eGFR}, \mathrm{mL} / \mathrm{min} / 1.73 \mathrm{~m}^{2}$ & $48.5(34.5-57.5)$ \\
\hline Fasting insulin, mlU/L & $18.2(14.4-21.9)$ \\
\hline HOMA-IR & $4.8(3.4-6.5)$ \\
\hline hs-CRP, mg/L & $2.9(1.1-7.4)$ \\
\hline Interleukin-6, pg/mL & $4.5(2.4-6.8)$ \\
\hline Urine microalbumin, mg/L & $15.0(7.5-43.4)$ \\
\hline \multicolumn{2}{|l|}{ Cardiovascular function, median (IQR) } \\
\hline Systolic blood pressure, $\mathrm{mmHg}$ & $131(123-146)$ \\
\hline Diastolic blood pressure, $\mathrm{mmHg}$ & $65(61-76)$ \\
\hline Rest heart rate, per minute & $72(64-78)$ \\
\hline Stress heart rate, per minute & $94(84-103)$ \\
\hline Rest myocardial blood flow, $\mathrm{mL} / \mathrm{min} / \mathrm{g}$ & $0.8(0.7-0.9)$ \\
\hline Stress myocardial blood flow, mL/min/g & $1.7(1.3-2.2)$ \\
\hline Coronary flow reserve & $1.9(1.7-2.4)$ \\
\hline Rest left ventricular ejection fraction, $\%$ & $60.0(52.0-67.0)$ \\
\hline Stress left ventricular ejection fraction, $\%$ & $63.0(54.5-70.0)$ \\
\hline Summed stress score & $0(0-6)$ \\
\hline Summed rest score & $0(0-0)$ \\
\hline Summed difference score & $0(0-5)$ \\
\hline
\end{tabular}

$\mathrm{IQR}=$ interquartile range, $\mathrm{MI}=$ myocardial infarction, $\mathrm{eGFR}=$ estimated glomerular filtration rate, $\mathrm{HDL}=$ high-density lipoprotein, $\mathrm{LDL}=$ low-density lipoprotein, HOMA-IR = Homeostatic Model Assessment of Insulin Resistance (normal $<3$ ), hs-CRP $=$ high sensitivity $\mathrm{C}$-reactive protein
Table 2 Unadjusted linear regression analysis for the association between serum uric acid and cardiometabolic function $(n=44)$

\begin{tabular}{lll}
\hline Variables $^{\mathrm{a}}$ & Standardized coefficient (SE) & $P$-value \\
\hline Coronary flow reserve & $0.04(0.35)$ & 0.90 \\
Stress myocardial blood flow & $-0.20(0.43)$ & 0.64 \\
Interleukin-6 & $-0.46(1.00)$ & 0.65 \\
Serum creatinine & $0.87(0.33)$ & 0.01 \\
HOMA-IR & $0.76(1.04)$ & 0.47 \\
hs-CRP & $-1.47(1.56)$ & 0.35 \\
eGFR & $-1.23(0.38)$ & 0.002 \\
\hline
\end{tabular}

${ }^{\mathrm{a}} \mathrm{All}$ the variables were log-transformed. $\mathrm{SE}=$ standard error, eGFR $=$ estimated glomerular filtration rate, HOMA-IR = Homeostatic Model Assessment of Insulin Resistance, hs-CRP $=$ high sensitivity C-reactive protein

Elevated serum uric acid levels are thought to cause endothelial dysfunction via oxidative stress, micro-inflammation, lipid oxidation, and inhibition of nitric oxide production [38, 39]. However, the causality of such associations has not been proven [40, 41]. In this cross-sectional study of 44 patients with metabolic syndrome and asymptomatic hyperuricemia, $58 \%$ had abnormally low CFR (i.e., CFR $<2.0$ ) known to be an independent predictor for worse cardiovascular risk [12, $13,16,17]$. However, we found that SUA level was not associated with CFR, stress MBF, or HOMA-IR. Both unadjusted and adjusted analyses consistently yielded the null results. Due to the nature of the cross-sectional design, we were unable to determine an association between the duration of hyperuricemia and CFR.

There are several explanations for our null findings. First, it is possible that our study did not find any association between SUA and coronary vascular function or insulin resistance because our study was limited to those with hyperuricemia. Second, it is possible that hyperuricemia is not causally associated with coronary vascular function or insulin resistance in the absence of gout. Third, moderate hyperuricemia might not have a strong relationship with CFR even if SUA itself is causally related to cardiovascular risk. However, our results are consistent with another study of 382 patients with and without gout which showed no association between SUA level and CFR [26]. Fourth, since most patients in our study are older and have many other known strong cardiovascular risk factors such as obesity, hypertension, renal dysfunction, and diabetes, SUA may not have any additional effect on patients' coronary vascular function even if it has a modest causal association with cardiometabolic risk. Third, this pilot study may be underpowered particularly at the level of moderately, not severely, high SUA. Fourth, since we did not have a normouricemic group to compare with, the difference in patients' SUA levels might have been relatively too small. 
Table 3 Multivariable linear regression analysis for the association between serum uric acid and cardiometabolic function

\begin{tabular}{|c|c|c|c|}
\hline & Adjusted for & Standardized coefficient (SE) & P-value \\
\hline \multicolumn{4}{|c|}{ All patients $(n=44)$} \\
\hline \multirow[t]{3}{*}{ CFR } & Age, sex & $0.04(0.35)$ & 0.92 \\
\hline & Age, sex, diabetes, BMI, SSS, Cr & $0.07(0.39)$ & 0.86 \\
\hline & Age, sex, diabetes, BMI, SSS, Cr, IL-6, and hs-CRP & $-0.12(0.42)$ & 0.78 \\
\hline \multirow[t]{3}{*}{ Stress MBF } & Age, sex & $-0.19(0.40)$ & 0.63 \\
\hline & Age, sex, diabetes, BMI, SSS, Cr & $-0.35(0.44)$ & 0.43 \\
\hline & Age, sex, diabetes, BMI, SSS, Cr, IL-6, and hs-CRP & $-0.52(0.47)$ & 0.28 \\
\hline \multicolumn{4}{|c|}{ Patients with summed stress score $\leq 3(n=28)$} \\
\hline \multirow[t]{3}{*}{ CFR } & Age, sex & $0.17(0.43)$ & 0.69 \\
\hline & Age, sex, diabetes, BMI, SSS, Cr & $0.21(0.38)$ & 0.60 \\
\hline & Age, sex, diabetes, BMI, SSS, Cr, IL-6, and hs-CRP & $0.09(0.43)$ & 0.83 \\
\hline \multirow[t]{3}{*}{ Stress MBF } & Age, sex & $-0.13(0.42)$ & 0.76 \\
\hline & Age, sex, diabetes, BMI, SSS, Cr & $-0.13(0.43)$ & 0.76 \\
\hline & Age, sex, diabetes, BMI, SSS, Cr, IL-6, and hs-CRP & $-0.23(0.47)$ & 0.63 \\
\hline \multicolumn{4}{|c|}{ Patients without diabetes $(n=25)$} \\
\hline \multirow[t]{3}{*}{ HOMA-IR } & Age, sex & $1.87(1.30)$ & 0.17 \\
\hline & Age, sex, BMl & $1.36(1.26)$ & 0.29 \\
\hline & Age, sex, BMI, IL-6 and hs-CRP & $2.08(1.21)$ & 0.10 \\
\hline
\end{tabular}

$\mathrm{SE}=$ standard error, $\mathrm{CFR}=$ coronary flow reserve, $\mathrm{MBF}=$ myocardial blood flow, $\mathrm{BMI}=$ body mass index, $\mathrm{SSS}=$ summed stress $\mathrm{score}, \mathrm{Cr}=\mathrm{serum} \mathrm{creatinine}, \mathrm{IL}=$ interleukin, hs-CRP = high sensitivity C-reactive protein, HOMA-IR = Homeostatic Model Assessment of Insulin Resistance

A few prior studies examined the presence of subclinical urate deposits in patients with asymptomatic hyperuricemia using musculoskeletal ultrasound $[42,43]$. DECT is a newer imaging modality that allows specific detection and volume measurement of urate crystals in the joints or tendons among patients with gout [18]. A validation study of DECT for gout showed a high specificity over $93 \%$ but a moderate sensitivity below $80 \%$ [19]. However, the sensitivity of DECT is noted to be low in non-tophaceous gout [44]. A few studies used DECT to assess subclinical urate deposits in patients with asymptomatic hyperuricemia. In a previous study of 25 patients with asymptomatic hyperuricemia (SUA $\geq 9.0 \mathrm{mg} / \mathrm{dL}$ ), $24 \%$ were noted to have subclinical urate deposits in the joints and tendons based on the DECT scans of the feet [23]. In a cohort of renal transplant patients with asymptomatic hyperuricemia $(n=27$, median SUA $=7.9 \mathrm{mg} / \mathrm{dL}$ ), only 1 patient had quadriceps tendon deposition. However, none had articular or renal urate deposits [22]. In the present study, we also did not find any DECT-detectable urate deposits in the carotid arteries among hyperuricemic patients. It may be partially explained by the fact that most patients were hyperuricemic but their SUA were not too high with the upper quartile SUA level of $8.4 \mathrm{mg} / \mathrm{dL}$. Furthermore, the sensitivity of DECT for the vasculature in asymptomatic hyperuricemia patient may be too low as $15 \%$ of the study cohort had DECT-positive urate deposits in their feet [25].
While it has been reported that urate deposits were present in the mitral valve, aortic and tricuspid valves and the endocardium in patients with gout, [45-47]. it remains unknown whether patients with asymptomatic hyperuricemia have urate deposits in the vasculature including the carotid arteries.

There are limitations in this study. First, this is a cross-sectional study without longitudinal followup. While we found no association between SUA and coronary vascular function and insulin resistance at one point in time, there could be an association between changes in SUA and changes in cardiometabolic risks. Second, since we included only asymptomatic hyperuricemic patients, the association between SUA and cardiometabolic risks may be different for patients with gout. Third, this study was performed at a single academic center and relied on active patient participation. Thus, the generalizability of our results may be limited. Patients who were enrolled but did not complete the study visit were older and more likely to be male and had lower SUA levels. Fourth, while this is one of the largest studies on asymptomatic hyperuricemia, the study size may not be adequate. In particular, only 25 patients (56.8\%) had no diabetes. Thus, the subgroup analysis that included only non-diabetic patients on the association between SUA and HOMA-IR may be underpowered. Fifth, the final models were adjusted for several important predictors of cardiometabolic 
risk including age, sex, renal function, a summed stress score (i.e., a marker of myocardial scar and ischemia), and markers of systemic inflammation (i.e., IL-6 and hs-CRP), there may be residual confounding.

\section{Conclusions}

In this cross-sectional study of patients with metabolic syndrome and asymptomatic hyperuricemia, we found no relationship between SUA, coronary vascular function, and other cardiometabolic markers. Further studies are needed to confirm our findings. None of the patients had DECT-detectable subclinical urate deposits in the neck.

\section{Abbreviations}

BMl: body mass index; CAD: coronary artery disease; CFR: coronary flow reserve; CRP: c-reactive protein; DECT: dual-energy computed tomography; HOMA-IR: Homeostatic Model Assessment of Insulin Resistance; IL: interleukin; IQR: interquartile range; MBF: myocardial blood flow; MetS: metabolic syndrome; PET: positron emission tomography; SUA: serum uric acid

\section{Funding}

This study was funded by an investigator-initiated research grant from AstraZeneca. However, the study was conducted by the authors independent of the sponsor. The sponsor was given the opportunity to make non-binding comments on a draft of the manuscript, but the authors retained the right of publication and to determine the final wording.

\section{Availability of data and material}

The dataset that we generated and used during this study is kept at the Brigham and Women's Hospital (PI: Kim); however, the dataset is not publicly available to protect study participants' confidentiality.

\section{Disclosures}

This study was supported by an investigator-initiated grant from AstraZeneca/Ironwood Pharmaceuticals. The study was conducted by the authors independent of the sponsor. The sponsor was given the opportunity to make non-binding comments on a draft of the manuscript, but the authors retained the right of publication and to determine the final wording.

\section{Authors' contributions}

SCK had full access to all of the data in the study and takes responsibility for the integrity of the data and the accuracy of the data analysis. She is the guarantor for the study. SCK, MFD, RKG, KV, PW, AW, ZY, FL, AC, CFB, SS, and DHS conceived and designed the study. SCK, MFD, RKG, KV, PW, AW, ZY, FL, AC, CFB, SS, and DHS collected and analyzed the data. SCK, MFD, RKG, KV, PW, AW, $Z Y, F L, A C, C F B, S S$, and DHS interpreted the data together and critically revised the manuscript for important intellectual content. SCK drafted the paper. All authors have given final approval of the version to be published.

\section{Ethics approval and consent to participate}

The study protocol was approved by the Institutional Review Board of the Brigham and Women's Hospital. All included patients gave us written informed consent before participating in this study.

\section{Consent for publication}

$\mathrm{n} / \mathrm{a}$

\section{Competing interests}

Kim has received research support from Lilly, Pfizer, Genentech, Bristol-Myers Squibb, and Merck for unrelated studies.

Solomon has received research/funding support from Amgen, AstraZeneca, Genentech, Lilly and CORRONA, received royalties from UpToDate and served in unpaid roles in studies funded by Pfizer.

Di Carli, Garg, Vanni, Wang, Wohlfahrt, Yu, Lu, Campos, Bibbo, and Smith have nothing to disclose.

\section{Publisher's Note}

Springer Nature remains neutral with regard to jurisdictional claims in published maps and institutional affiliations.

\section{Author details}

${ }^{1}$ Division of Pharmacoepidemiology and Pharmacoeconomics, Department of Medicine, Brigham and Women's Hospital, Harvard Medical School, 1620 Tremont St, Suite 3030, Boston, MA 02120, USA. ²Division of Rheumatology, Immunology, and Allergy, Department of Medicine, Brigham and Women's Hospital, Harvard Medical School, Boston, MA, USA. ${ }^{3}$ Division of Nuclear Medicine, Department of Radiology, Brigham and Women's Hospital, Harvard Medical School, Boston, MA, USA. ${ }^{4}$ Division of Cardiovascular Medicine, Department of Medicine, Brigham and Women's Hospital, Harvard Medical School, Boston, MA, USA. 'Division of Endocrinology, Diabetes \& Hypertension, Department of Medicine, Brigham and Women's Hospital, Harvard Medical School, Boston, MA, USA. 'Department of Radiology, Brigham and Women's Hospital, Harvard Medical School, Boston, MA, USA.

Received: 14 December 2017 Accepted: 11 June 2018

Published online: 20 June 2018

\section{References}

1. Kim S, Garg R, Smith S, Wohlfahrt A, Campos A, Vanni K, Lee L, Wang P, Yu Z, Di Carli M, et al. Cardiometabolic Risk and Subclinical Urate Deposits in Patients with Symptomatic Hyperuricemia and Metabolic Syndrome [abstract]. Arthritis Rheumatol (Hoboken, NJ). 2016;68(suppl 10).

2. Choi HK, Ford ES, Li C, Curhan G. Prevalence of the metabolic syndrome in patients with gout: the third National Health and nutrition examination survey. Arthritis Rheum. 2007:57(1):109-15.

3. Kim SY, Guevara JP, Kim KM, Choi HK, Heitjan DF, Albert DA. Hyperuricemia and risk of stroke: a systematic review and meta-analysis. Arthritis Rheum. 2009;61(7):885-92.

4. Kim SY, Guevara JP, Kim KM, Choi HK, Heitjan DF, Albert DA. Hyperuricemia and coronary heart disease: a systematic review and meta-analysis. Arthritis Care Res (Hoboken). 2010;62(2):170-80.

5. Kok VC, Horng JT, Lin HL, Chen YC, Chen YJ, Cheng KF. Gout and subsequent increased risk of cardiovascular mortality in non-diabetics aged 50 and above: a population-based cohort study in Taiwan. BMC Cardiovasc Disord. 2012;12:108

6. Kuo CF, See LC, Yu KH, Chou IJ, Chiou MJ, Luo SF. Significance of serum uric acid levels on the risk of all-cause and cardiovascular mortality. Rheumatology (Oxford). 2013;52(1):127-34.

7. Lottmann K, Chen X, Schadlich PK. Association between gout and all-cause as well as cardiovascular mortality: a systematic review. Curr Rheumatol Rep. 2012;14(2):195-203.

8. Krishnan E, Akhras KS, Sharma H, Marynchenko M, Wu EQ, Tawk R, Liu J, Shi $\mathrm{L}$. Relative and attributable diabetes risk associated with hyperuricemia in US veterans with gout. QJM : monthly journal of the Association of Physicians. 2013;106(8):721-9.

9. Krishnan E, Pandya BJ, Chung L, Hariri A, Dabbous O. Hyperuricemia in young adults and risk of insulin resistance, prediabetes, and diabetes: a 15-year follow-up study. Am J Epidemiol. 2012;176(2):108-16.

10. Alexanderson E, Garcia-Rojas L, Jimenez M, Jacome R, Calleja R, Martinez A, Ochoa JM, Meave A, Alexanderson G. Effect of ezetimibe-simvastatine over endothelial dysfunction in dyslipidemic patients: assessment by $13 \mathrm{~N}$-ammonia positron emission tomography. J Nucl Cardiol : official publication of the American Society of Nuclear Cardiology. 2010;17(6):1015-22.

11. Di Carli MF, Janisse J, Grunberger G, Ager J. Role of chronic hyperglycemia in the pathogenesis of coronary microvascular dysfunction in diabetes. $J$ Am Coll Cardiol. 2003;41(8):1387-93.

12. Fukushima K, Javadi MS, Higuchi T, Lautamaki R, Merrill J, Nekolla SG, Bengel FM. Prediction of short-term cardiovascular events using quantification of global myocardial flow reserve in patients referred for clinical 82Rb PET perfusion imaging. J Nucl Medi : official publication, Society of Nuclear Medicine. 2011;52(5):726-32.

13. Herzog BA, Husmann L, Valenta I, Gaemperli O, Siegrist PT, Tay FM, Burkhard $\mathrm{N}$, Wyss CA, Kaufmann PA. Long-term prognostic value of $13 \mathrm{~N}$-ammonia myocardial perfusion positron emission tomography added value of coronary flow reserve. J Am Coll Cardiol. 2009;54(2):150-6.

14. Taqueti VR, Everett BM, Murthy VL, Gaber M, Foster CR, Hainer J, Blankstein R, Dorbala S, Di Carli MF. Interaction of impaired coronary flow reserve and 
cardiomyocyte injury on adverse cardiovascular outcomes in patients without overt coronary artery disease. Circulation. 2015;131(6):528-35.

15. Gould KL, Ornish D, Scherwitz L, Brown S, Edens RP, Hess MJ, Mullani N, Bolomey L, Dobbs F, Armstrong WT, et al. Changes in myocardial perfusion abnormalities by positron emission tomography after long-term, intense risk factor modification. Jama. 1995;274(11):894-901.

16. Murthy VL, Naya M, Foster CR, Hainer J, Gaber M, Di Carli G, Blankstein R, Dorbala S, Sitek A, Pencina M, et al. Improved cardiac risk assessment with noninvasive measures of coronary flow reserve. Circulation. 2011;124(20):2215-24.

17. Ziadi MC, Dekemp RA, Williams KA, Guo A, Chow BJ, Renaud JM, Ruddy TD, Sarveswaran N, Tee RE, Beanlands RS. Impaired myocardial flow reserve on rubidium-82 positron emission tomography imaging predicts adverse outcomes in patients assessed for myocardial ischemia. J Am Coll Cardiol. 2011;58(7):740-8.

18. Choi HK, Al-Arfaj AM, Eftekhari A, Munk PL, Shojania K, Reid G, Nicolaou S. Dual energy computed tomography in tophaceous gout. Ann Rheum Dis. 2009;68(10):1609-12.

19. Choi HK, Burns LC, Shojania K, Koenig N, Reid G, Abufayyah M, Law G, Kydd AS, Ouellette $H$, Nicolaou $S$. Dual energy $C T$ in gout: a prospective validation study. Ann Rheum Dis. 2012;71(9):1466-71.

20. Lee YH, Song GG. Diagnostic accuracy of dual-energy computed tomography in patients with gout: a meta-analysis. Semin Arthritis Rheum. 2017;47(1):95-101. https://doi.org/10.1016/j.semarthrit.2017.03.002. Epub 2017 Mar 8

21. Breuer GS, Bogot N, Nesher G. Dual-energy computed tomography as a diagnostic tool for gout during intercritical periods. Int J Rheum Dis. 2016; 19(12):1337-41.

22. Kimura-Hayama E, Criales-Vera S, Nicolaou S, Betanzos JL, Rivera Y, Alberu J, Rull-Gabayet M, Hernandez-Molina G. A pilot study on dual-energy computed tomography for detection of urate deposits in renal transplant patients with asymptomatic hyperuricemia. J Clin Rheumatol : practical reports on rheumatic \& musculoskeletal diseases. 2014;20(6):306-9.

23. Dalbeth N, House ME, Aati O, Tan P, Franklin C, Horne A, Gamble GD, Stamp LK, Doyle AJ, McQueen FM. Urate crystal deposition in asymptomatic hyperuricaemia and symptomatic gout: a dual energy CT study. Ann Rheum Dis. 2015;74(5):908-11.

24. Third Report of the National Cholesterol Education Program. NCEP expert panel on detection, evaluation, and treatment of high blood cholesterol in adults adult treatment panel III final report. Circulation. 2002;106(25):3143-421.

25. Wang P, Smith SE, Garg R, Lu F, Wohlfahrt A, Campos A, Vanni K, Yu Z, Solomon DH, Kim SC. Identification of monosodium urate crystal deposits in patients with asymptomatic hyperuricemia using dual-energy CT. RMD open. 2018;4(1):e000593.

26. Kim SC, Shah NR, Rogers JR, Bibbo CF, Di Carli MF, Solomon DH. Assessment of coronary vascular function with cardiac PET in relation to serum uric acid. PLoS One. 2018;13(2):e0192788.

27. Di Carli MF, Dorbala S, Meserve J, El Fakhri G, Sitek A, Moore SC. Clinical myocardial perfusion PET/CT. J Nucl Med : official publication, Society of Nuclear Medicine. 2007:48(5):783-93.

28. Beanlands RS, Muzik O, Melon P, Sutor R, Sawada S, Muller D, Bondie D, Hutchins GD, Schwaiger M. Noninvasive quantification of regional myocardial flow reserve in patients with coronary atherosclerosis using nitrogen-13 ammonia positron emission tomography. Determination of extent of altered vascular reactivity. J Am Coll Cardiol. 1995;26(6):1465-75.

29. Di Carli M, Czernin J, Hoh CK, Gerbaudo VH, Brunken RC, Huang SC, Phelps ME, Schelbert HR. Relation among stenosis severity, myocardial blood flow, and flow reserve in patients with coronary artery disease. Circulation. 1995;91(7):1944-51.

30. El Fakhri G, Kardan A, Sitek A, Dorbala S, Abi-Hatem N, Lahoud Y, Fischman A, Coughlan M, Yasuda T, Di Carli MF. Reproducibility and accuracy of quantitative myocardial blood flow assessment with (82) Rb PET: comparison with (13) N-ammonia PET. J Nucl Med : official publication, Society of Nuclear Medicine. 2009:50(7):1062-71.

31. El Fakhri G, Sitek A, Guerin B, Kijewski MF, Di Carli MF, Moore SC. Quantitative dynamic cardiac 82Rb PET using generalized factor and compartment analyses. J Nucl Med : official publication, Society of Nuclear Medicine. 2005;46(8):1264-71.

32. Cerqueira MD, Weissman NJ, Dilsizian V, Jacobs AK, Kaul S, Laskey WK, Pennell DJ, Rumberger JA, Ryan T, Verani MS. Standardized myocardia segmentation and nomenclature for tomographic imaging of the heart. A statement for healthcare professionals from the cardiac imaging Committee of the Council on clinical cardiology of the American Heart Association. Int J Cardiovasc Imaging. 2002;18(1):539-42
33. Machac J, Bacharach SL, Bateman TM, Bax JJ, Beanlands R, Bengel F, Bergmann SR, Brunken RC, Case J, Delbeke D, et al. Positron emission tomography myocardial perfusion and glucose metabolism imaging. J Nucl Cardiol : official publication of the American Society of Nuclear Cardiology. 2006;13(6):e121-51.

34. Yoshinaga K, Chow BJ, Williams K, Chen L, deKemp RA, Garrard L, Lok-Tin Szeto A, Aung M, Davies RA, Ruddy TD, et al. What is the prognostic value of myocardial perfusion imaging using rubidium-82 positron emission tomography? J Am Coll Cardiol. 2006;48(5):1029-39.

35. Matthews DR, Hosker JP, Rudenski AS, Naylor BA, Treacher DF, Turner RC. Homeostasis model assessment: insulin resistance and beta-cell function from fasting plasma glucose and insulin concentrations in man. Diabetologia. 1985;28(7):412-9.

36. Grayson PC, Kim SY, LaValley M, Choi HK. Hyperuricemia and incident hypertension: a systematic review and meta-analysis. Arthritis Care Res (Hoboken). 2011;63(1):102-10.

37. Perez-Ruiz F, Martínez-Indart L, Carmona L, Herrero-Beites AM, Pijoan Jl, Krishnan E. Tophaceous gout and high level of hyperuricaemia are both associated with increased risk of mortality in patients with gout. Ann Rheum Dis. 2013;73(1):177-82. https://doi.org/10.1136/annrheumdis-2012202421. Epub 2013 Jan 12

38. Wang Y, Bao X. Effects of uric acid on endothelial dysfunction in early chronic kidney disease and its mechanisms. Eur J Med Res. 2013;18(1):26.

39. Khosla UM, Zharikov S, Finch JL, Nakagawa T, Roncal C, Mu W, Krotova K, Block ER, Prabhakar S, Johnson RJ. Hyperuricemia induces endothelial dysfunction. Kidney Int. 2005;67(5):1739-42.

40. Keenan T, Zhao W, Rasheed A, Ho WK, Malik R, Felix JF, Young R, Shah N, Samuel M, Sheikh N, et al. Causal assessment of serum urate levels in Cardiometabolic diseases through a Mendelian randomization study. J Am Coll Cardiol. 2016;67(4):407-16.

41. White J, Sofat R, Hemani G, Shah T, Engmann J, Dale C, Shah S, Kruger FA, Giambartolomei C, Swerdlow DI, et al. Plasma urate concentration and risk of coronary heart disease: a Mendelian randomisation analysis. Lancet Diabetes Endocrinol. 2016;4(4):327-36.

42. De Miguel E, Puig JG, Castillo C, Peiteado D, Torres RJ, Martin-Mola E. Diagnosis of gout in patients with asymptomatic hyperuricaemia: a pilot ultrasound study. Ann Rheum Dis. 2012:71(1):157-8.

43. Puig JG, Beltran LM, Mejia-Chew C, Tevar D, Torres RJ. Ultrasonography in the diagnosis of asymptomatic hyperuricemia and gout. Nucleosides Nucleotides Nucleic Acids. 2016;35(10-12):517-23.

44. Baer AN, Kurano T, Thakur UJ, Thawait GK, Fuld MK, Maynard JW, McAdamsDeMarco M, Fishman EK, Carrino JA. Dual-energy computed tomography has limited sensitivity for non-tophaceous gout: a comparison study with tophaceous gout. BMC Musculoskelet Disord. 2016;17:91.

45. Emmerson BT. Atherosclerosis and urate metabolism. Aust NZ J Med. 1979; 9(4):451-4.

46. Jr.MH: Pathology of the cardiovascular system in chronic Ren Fail In: Management of Cardiovascular Disease in Ren Fail Volume 1, EDN Edited by DT L, RL P, W L. Phiadelphia: FA Davis; 1981

47. McAllister H Jr, Buja L, Ferrans V. Valvular heart disease: anatomic abnormalities. In: Willerson J, Cohn J, Wellens H, Holmes Jr D, editors. Cardiovascular Medicine, vol. 20007. 3rd ed: Springer Science \& Business Media. p. 372

Ready to submit your research? Choose BMC and benefit from:

- fast, convenient online submission

- thorough peer review by experienced researchers in your field

- rapid publication on acceptance

- support for research data, including large and complex data types

- gold Open Access which fosters wider collaboration and increased citations

- maximum visibility for your research: over $100 \mathrm{M}$ website views per year

At BMC, research is always in progress.

Learn more biomedcentral.com/submissions 